\title{
Computer-Assisted Interpreting Technologies and Interpreter Cognition: A Product and Process-Oriented Perspective
}

\author{
Christopher D. Mellinger
}

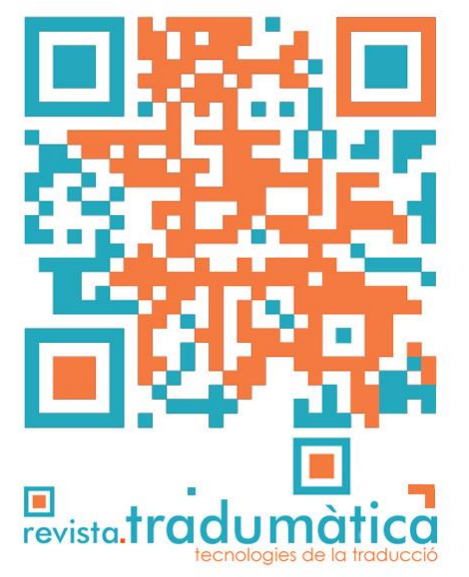

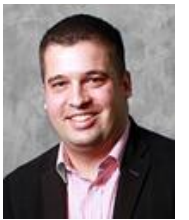

Christopher D.

Mellinger

Assistant Professor of Spanish Interpreting and Translation Studies, UNC Charlotte cmelling@uncc.edu; ORCID: $\underline{0000-0003-4915-8821}$
Abstract

Research on technology-enabled and technology-mediated interpreting to date has taken a largely product-oriented approach to understand the role of technology during interpreting. In response to calls for additional empirical research on the intersection of interpreting, technology, and cognition, this article argues for the inclusion of processoriented research and outlines several areas of potential investigation.

Keywords: computer-assisted interpreting technologies; interpreter cognition; process research

Resum

Fins ara, la recerca sobre la interpretació assistida i intercedida per la tecnologia ha adoptat un enfocament centrat principalment en el producte per tal d'entendre el paper de la tecnologia durant l'exercici de la interpretació. A fi de respondre a la necessitat d'una recerca empírica addicional sobre la intersecció entre la interpretació, la tecnologia i la cognició, aquest article posa de manifest la necessitat d'incloure una recerca orientada al procés de la interpretació i determina diverses àrees de recerca de possible interès.

Paraules clau: tecnologies d'interpretació assistida per ordinador; cognició d'intèrprets; investigació orientada al procés de la interpretació

Resumen

Hasta el momento, la investigación sobre la interpretación asistida y mediada por tecnología ha adoptado un enfoque centrado principalmente en la interpretación como producto para entender el papel de la tecnología durante esta actividad. En respuesta a la llamada de investigación empírica adicional sobre las intersecciones entre interpretación, tecnología y cognición, este articulo aboga por la inclusión de investigación orientada hacia el proceso de la interpretación e identifica unas áreas de investigación de posible interés.

Palabras clave: tecnologías de interpretación asistida por ordenador; cognición de intérpretes; investigación orientada hacia el proceso de la interpretación 


\section{Introduction}

In the past few years, the development of interpreting technologies and the impact they have on the daily work of interpreters has drawn the attention of language industry stakeholders and interpreting studies researchers alike. While new technologies that integrate wearable and mobile technologies, machine interpreting and automated speech recognition regularly figure into professional and academic conference programs, international standards have been developed to account for the changing profile and work requirements of interpreting in a range of settings (e.g., ISO 20109: 2016; ISO/FDIS 20539). In addition, organizations and companies have increasingly adopted video and remote interpreting as a means to provide interpreting services (cf. Braun, 2019). Whereas many proponents of interpreting technologies regularly tout the benefits, others are more cautious regarding their merits. Nevertheless, the sustained interest in interpreting technologies points to the likely permanence of these technologies in the work of interpreters (cf. Kalina and Ziegler, 2015).

The widespread use of interpreting technologies has placed greater emphasis on the need to understand the impact these technologies have on the interpreter's task. Fantinuoli (2017, 2018a, 2018b) identifies this crucial need for additional research and calls for empirical studies to examine technology-mediated interpreting as well as the impact these tools have on interpreter performance. This "technological turn" in interpreting studies, to borrow Fantinuoli's (2018b) term, is one that presents both opportunities and challenges to the interpreting community, and there is undoubtedly a need for more research on the role technology plays in enabling, mediating and constraining interpreting.

Since Fantinuoli's appeal to the research community, several collections of studies have been published that specifically address the intersection of interpreting and technology (e.g., Fantinuoli, 2018c; Pokorn and Mellinger, 2018) along with a growing number of articles, white papers, and industry reports. This increase is indeed promising, however, one area yet to be explored in great depth is the intersection of technology and interpreter cognition. Recognizing the importance of this type of research is nothing new: Moser-Mercer (1997) identified technology-mediated or technology-enabled interpreting and its impact on interpreter cognition as an area primed for growth. In reviewing several of the challenges facing interpreting studies scholars to conduct work on telecommunications and the practice of interpreting, Moser-Mercer (1997) suggests an inter- and multidisciplinary approach to answer questions surrounding interpreter cognition - an approach that has borne fruit in the intervening years.

In response to Fantinuoli's (2018a, 2018b) call for more empirical research, and in line with Moser-Mercer's (1997) discussion of the challenges of researching interpreter cognition, this article advocates for a process-oriented approach to investigate computerassisted interpreting. To do so, the article first outlines current product-oriented approaches to researching interpreting technologies and interpreter cognition. This review illustrates potential disconnects between these two areas, thereby requiring greater methodological reflection on how to bridge this scholarship. It then presents processoriented approaches to interpreting studies as a complement to the extant literature. 
Particular emphasis is placed on workplace and training settings as a means to illustrate the utility of combining product- and process-oriented research approaches to computerassisted interpreting.

\section{Product-oriented research}

Research on interpreting technologies has often relied on product data to examine questions related to a range of topics of interest to interpreting scholars, such as quality, agency, and role: transcripts or recordings of interpreters' renditions, audio or video recordings of interpreters' performance or survey/questionnaire data. These data are derived from various experimental, quasi-experimental, and observational research designs that allow the impact technologies have on the interpreting task to be examined (see Fantinuoli, 2018a for an overview). This approach to studying the interpreting process is useful to understand at the macro-level what types of changes occur when introducing specific technologies into the interpreting task and to draw conclusions based on inferences about what product data may reveal concerning interpreter cognition.

The scope of inquiry on interpreting technologies continues to expand and while it is impossible to review every area of scholarship, two have received considerable attention, namely interpreting technologies in the workplace and in training settings. By way of example, the immediate impact that video and remote interpreting have had on professional interpreters has drawn the attention of both practitioners and researchers alike. Scholars such as Braun (2013, 2019) and Ziegler and Gigliobianco (2018) illustrate how the interpreting task changes based on the configuration of the various speakers and the interpreter. Moreover, this research identifies challenges faced by interpreters that could make their work more difficult or require different strategies to resolve issues encountered during the communicative event. This work largely focuses on the role that technology plays in enabling interpreting in new configurations, or in creating new contexts for interpreting work to take place.

Other scholarship has focused on enhancing interpreter performance during the task itself. The range of technologies now available to interpreters is much greater in light of advances in mobile computing and mobile devices; interpreter workstations and mobile computing now figure into common interpreter workplace conditions (Winteringham, 2010; Corpas Pastor, 2018). For instance, research on tablet computers has identified specific software features that interpreters find useful or distracting when interpreting consecutively (Goldsmith, 2018). The ability to take notes digitally may provide a number of advantages compared to traditional pen-and-paper methods, yet it requires a different approach to interpreter preparation and performance. In the interpreting booth, technology is beginning to address challenges often faced by simultaneous interpreters; for example, automated speech recognition can recognize numbers in speech and present them visually to an interpreter (Desmet, Vandierendonck, and Defrancq, 2018). This technological support may be useful to reduce the cognitive load of interpreters when working in the booth and improve accuracy or other aspects of the interpreting task. Speech recognition, in particular, is garnering greater attention of researchers given the 
potential it has to support interpreters in real-time (Fantinuoli, 2017; Ortiz and Cavallo, 2018).

Scholars have also examined the role of technology in educational and training contexts (e.g., Sandrelli and Manuel Jerez, 2007; Kerremans, et al. 2019). This line of inquiry continues to flourish due to new developments in educational technologies and the growing need to prepare students to work in professional contexts. Particular interest has been placed on new teaching modalities, such as hybrid, distance, and online education (for an overview, see Sandrelli, 2015). Previous work on synchronous learning in the interpreting classroom showed challenges for both instructors and students (Ko and Chen, 2011), while more recent scholarship that offers both synchronous and asynchronous modes of teaching appears to be overcoming these issues. For instance, Darden and Maroney (2018) discuss the role that learning management systems have on the ability to reach a wider audience and enroll students who are not able to be physically present in the interpreting classroom.

Beyond delivery modes, computer-assisted interpreter training (CAIT) has been the focus of a sustained line of inquiry. While some studies have focused on the students' perceptions of this type of learning (e.g., Lim, 2013) or the integration of specific CAIT tools in the classroom (e.g., Lee, 2014), others have focused on virtual reality environments or computer simulations designed to augment interpreter training (e.g., Hunt-Gómez and Gómez Moreno, 2015; Viljanmaa, 2018). The inclusion of these types of technologies present both pedagogical advantages and drawbacks, and scholars have begun to address the impact these have on learning outcomes and programmatic goals (e.g., Class and Moser-Mercer, 2013; Kerremans and Stengers, 2017).

These types of studies mentioned above lay the foundation for work on the impact interpreting technologies have on interpreter cognition in both professional and educational contexts; however, the influence technology has on cognition remains relatively unexplored. In some cases, results of these studies suggest the impact technologies have on interpreters' cognitive activity: change in cognitive load or attention, acquisition of interpreting competences, impact on working memory capacity. Likewise, authors often allude to future lines of research to explicitly test cognitive constructs that are often proffered as a rationale for observed behavior. Nevertheless, to conduct this type of work requires a complementary approach to research that allows for real-time data collection which examines the interpreting process as it unfolds.

\section{Process-oriented research}

Cognitive activity is not directly observable, and consequently, researchers must work with a range of methods to triangulate potential cognitive behavior. Translation process research studies commonly employ methods from psycholinguistics, cognitive psychology and human-computer interaction, and this type of work has been conducted for several decades (Shreve and Angelone 2010; Muñoz 2016). Commonly employed data collection methods in translation process research record translator behavior in real-time and associate their behavior with time codes as the participants complete their work, providing 
researchers with insight into decision-making behaviors that might otherwise not be visible in the final text or product. Research on translation technologies has employed these tools as well in order to understand how specific tools and resources can influence translator behavior.

Whereas process research that focuses on translator behavior can be automated to some extent using keystroke logging, eye-tracking or screen recording technologies, interpreting process research requires a different approach to understand interpreter cognition. Englund Dimitrova and Tiselius (2009, 2014), for instance, employ retrospective verbalizations to prompt participants to reflect on their work after it has been completed. These types of verbalizations are useful to understand interpreter decision-making strategies or areas of difficulty, at least to the extent that participants are aware of their behavior. These verbal protocols can be triangulated with the actual performance of interpreters to provide a more complete picture of the interpreting process (e.g., Tiselius, 2018).

Triangulating interpreter performance data with retrospective verbalizations may be one way that researchers can examine the impact of technology on interpreter cognition and behavior. Napier and Leneham (2011) adopt this approach when examining video remote interpreting in courtroom settings. While the findings focus primarily on whether video remote interpreting is a viable solution for providing language access, cognitive indicators were also observable. For instance, the researchers mention metalinguistic awareness related to clarifications and interpreter speed in their analysis of specific interpreter behavior. The inclusion of retrospective verbalizations allows researchers to re-visit observations made of the data with the participant, thereby clarifying potential decisions and avoiding misinterpretation of a specific behavior.

Corpus-based studies are another way in which researchers have investigated interpreter behavior and performance. In a review of almost twenty years of corpusbased interpreting studies research, Bendazzoli (2017) shows how interpreting studies corpora allow researchers to analyses interpreting in various modes and settings and how these corpora may be useful in the interpreting classroom. In many cases, these corpora have focused on spoken language interpreting, however, signed language interpreting researchers have also begun to reflect on the development of corpora to facilitate work in this area (e.g., Wehrmeyer, 2019). Unlike translation corpora which only record the final version of the text, interpreting corpora can also capture the entire rendition, including corrections, omissions or hesitations.

The additional linguistic features of an interpreter's rendition have been leveraged by researchers interested in interpreter cognition. As Setton (2011) asserts, corpora that are time-aligned - i.e., utterances can be aligned with the time at which they were spoken allow researchers to investigate cognitive behaviors and strategies employed by the interpreters performing the task. For example, Plevoets and Defrancq (2016) examine whether delivery rate, lexical density, and other measures of information load have an impact on interpreter performance, measured by speech disfluencies such as hesitations or utterances such as "uh(m)". This type of work has informed additional research on 
the cognitive load of interpreters, which illustrates how corpus data can elucidate the cognitive behavior of interpreters (Plevoets and Defrancq, 2018).

As in the case of retrospective verbalizations, corpus-based studies are another way in which technology can be investigated in relation to interpreter cognition. The same types of linguistic data - e.g., omissions, hesitations or speech disfluencies - that are recorded in interpreted renditions, can be analyzed in the light of questions related to interpreting technologies. Corpora of dialogue interpreting in remote or video interpreting configurations may also capture utterances specifically by the interpreter or interlocutors related to the technology itself: speakers may request repetitions because they did not understand a statement, or they may comment on not being able to hear or see due to the voice or video quality.

However, these types of indicators are not necessarily the result of technology or cognitive behavior, therefore, greater reflection is needed on the conditions under which renditions have been recorded. To give but one example, simultaneous interpreting renditions in international organizations are produced using technologies that ideally conform to best practices and that are likely permanent installations. In contrast, simultaneous renditions produced under different conditions or with different technology configurations may produce different results. Researchers will likely need to control as many extraneous variables as possible to isolate the technology under consideration as the independent variable in the study. While the ecological validity of tightly-controlled experimental studies may not mirror those of purely observational research, these types of studies help to establish a causal link between technology use and the variables of interest.

The previously described process-oriented approaches to interpreter cognition have certainly provided the foundation upon which technology and interpreting can be investigated, however, there are still other means by which they can be researched. Physiological measures, such as blood pressure and heart rate, have been used in process research on interpreting to investigate stress (e.g., Korpal, 2016). Psychophysiological measures such as galvanic skin response, EEGs, and pupillometrics are also being explored as a means to understanding the underlying cognitive behavior related to emotion and stress during interpreting (Muñoz, Calvo, and García, 2019).

These types of measures can complement existing research on interpreter technologies. For instance, Roziner and Shlesinger (2010) investigate stress in interpreting from an ergonomic perspective, focusing on measures related to thermal comfort, illumination, acoustic factors, and ventilation. This study employs two phases of data collection in which interpreters perform the same task but under different conditions (i.e., 'normal' conference conditions and 'remote' conference interpreting). While the selfreported data from Roziner and Shelsinger's (2010) point to the psychological impact that working remotely can have, additional physiological measures may help determine whether this finding is the result of prolonged work in a specific condition or as an immediate response to remote interpreting technologies.

Still other new recording technologies are being tested as a means to collect cognitive behavior data. Chen (2017), for example, examines pen recording as a potential means 
to capture more data about consecutive interpreting. While previous research on notetaking in interpreting focused solely on the final product of the notes, thereby limiting the type of information that could be gathered, Chen's work shows how pen distance, duration and speed can be recorded as well. Moreover, these recordings "not only tell us what interpreters' note-taking choices are, but also [...] how interpreters carry out those choices" (Chen, 2017: 4).

Beyond physical measures, process-oriented research on interpreting technologies are likely to benefit from psychometrically validated scales to better understand inherent and latent characteristics of interpreters. The use of surveys and questionnaires are quite common in interpreting studies, yet their utility ultimately relies on whether these instruments possess the necessary forms of validity and reliability (cf. Furr, 2018). Psychometrically validated scales that are specific to interpreting are scarce (with Angelelli, 2004 being a notable exception), yet several have been adapted for use in interpreting in recent years. For example, Mellinger and Hanson (2018) investigated the propensity to adopt specific technologies and interpreters' attitudes toward technology use during interpreting. To do so, they use several previously validated scales, while also adapting another for use in interpreting studies. This approach allows researchers working with different groups of participants to make more accurate comparisons across studies if reliable scales have been used.

Process-oriented research may also wish to look to human-computer interaction and cognitive ergonomics to see how interpreter cognition might be influenced by the use of specific technologies. For instance, researchers interested in mobile interpreting technologies may want to refer to Wilmer, Sherman, and Chein's (2017) review of the intersection of smart phones and cognition and the trends they identify in current scholarship on cognitive functioning and performance when working with mobile technologies. In a similar vein, scholars interested in team-based or remote interpreting ought to consider Thiemann, Hesse, and Kozlov's (2019) research on how people negotiate and collaborate in computer-mediated environments. These examples are by no means exhaustive, but referring to this type of work allows interpreting process researchers to ground their work in the extant literature and provides scholars with the opportunity to explore new methods and research designs to examine specific aspects of technology that have, as of yet, been explored.

\section{Conclusion}

The process-oriented methods described here are beneficial to the study of interpreting technologies and cognition not only in workplace settings but also educational contexts, and can augment existing product-based studies. Workplace studies, in particular, benefit from this type of analysis since they allow researchers to examine the impact that interpreting technologies have under professional working conditions. Professional and standards organizations, policy makers, and industry stakeholders need empirical research on the use of interpreting technologies to better understand the role that these technologies play in multilingual communication, and process research is an important component of this discussion. Scholarship in language industry settings, however, presents 
unique challenges and will likely require the collaboration of both researchers and industry partners (Mellinger, 2019). Nevertheless, the benefits of theoretically grounded and methodologically-sound research that incorporates both product and process data, outweigh the potential difficulties. Moreover, research on interpreting technologies in professional contexts establishes a point of reference for training programs that prepare interpreters for work in a range of settings.

By reviewing product and process-oriented approaches to interpreting studies research, this article attempts to advance Fantinuoli's (2017) call for additional empirical research on interpreting technologies. In particular, it advocates for a process-oriented approach to interpreting technologies research to better understand the impact that these tools have on interpreter cognition and behavior and to complement existing studies that have alluded to potential effects. While product-oriented studies allow scholars to infer potential cognitive behavior, real-time data coupled with measures that are specifically linked to cognitive constructs provide greater insight into the role of interpreting technologies in the work of professional interpreters.

\section{References}

Angelelli, C. (2004). Revisiting the Interpreter's Role: A study of conference, court and medical interpreters in Canada, Mexico, and the United States. Philadelphia: John Benjamins. 〈https://doi.org/10.1075/btl.55〉

Bendazzoli, C. (2017). Corpus-based interpreting studies: Past, present and future developments of a (wired) cottage industry, in: M. Russo; C. Bendazzoli; B. Defrancq (eds). Making Way in Corpus-based Interpreting Studies. London: Springer, pp. 1-19. 〈https://doi.org/10.1007/978-981-10-6199-8_1〉

Braun, S. (2013). Keep your distance? Remote interpreting in legal proceedings: A critical assessment of a growing practice, Interpreting, v. 15, n. 2, pp. 200-228. 〈https://doi.org/10.1075/intp.15.2.03bra〉

Braun, S. (2019). Technology and interpreting, in: M. O'Hagan (ed). The Routledge Handbook of Translation and Technology. New York: Routledge. 〈https://doi.org/10.4324/9781315311258-16〉

Chen, Sijia. (2017). Note-taking in consecutive interpreting: New data from pen recording. Translation \& Interpreting, v. 9, n. 1, pp. 4-23. 〈DOI: 10.12807/ti.109201.2017.a02>

Class, B.; Moser-Mercer, B. (2013). Training conference interpreter trainers with technology: a virtual reality, in: O. García Becerra, E.; M. Pradas Macías; R. BarrancoDroege (eds). Quality in Interpreting: Widening the Scope, Vol. 1. Granada: Comares, pp. 293-313.

Corpas Pastor, G. (2018). Tools for interpreters: The challenges that lie ahead. Current Trends in Translation Teaching and Learning E (CTTL E), n. 5, pp. 157-182. 
Darden, V.; Maroney, E. M. (2018). Craving to hear from you...': An exploration of mlearning in global interpreter education. Translation and Interpreting Studies, v. 13, n. 3, pp. 442-464. 〈https://doi.org/10.1075/tis.00024.dar〉

Desmet, B.; Vandierendonck, M.; Defrancq, B. (2018). Simultaneous interpretation of numbers and the impact of technological support, in: C. Fantinuoli (ed), Interpreting and Technology. Berlin: Language Science Press, pp. 13-27.

Englund Dimitrova, B.; Tiselius, E. (2009). Exploring retrospection as a research method for studying the translation process and the interpreting process, in: I. M. Mees; F. Alves; S. Göpferich (eds). Methodology, Technology and Innovation in Translation Process Research. Copenhagen: Samfundslitteratur, pp. 109-134.

Englund Dimitrova, B.; Tiselius, E. (2014). Retrospection in interpreting and translation: Explaining the process?. MonT/ Special Issue 1, pp: 177-200. 〈https://doi.org/10.6035/MonTI.2014.ne1.5〉

Fantinuoli, C. (2017). Speech recognition in the interpreter workstation, in: J. EstevesFerreira, et al. (eds). Proceedings of the 39th Conference Translating and the Computer. Geneva: Tradulex, pp. 25-34.

Fantinuoli, C. (2018a). Computer-assisted interpreting: Challenges and future perspectives, in: I. Durán-Muñoz; G. Corpas Pastor (eds). Trends in e-Tools and Resources for Translators and Interpreters. Leiden: Brill, pp. 153-174. 〈https://doi.org/10.1163/9789004351790_009〉

Fantinuoli, C. (2018b). Interpreting and technology: The upcoming technological turn, in: C. Fantinuoli (ed). Interpreting and Technology. Berlin: Language Science Press, pp. 1-12. 〈DOI:10.5281/zenodo.1493289〉

Fantinuoli, C. (ed). (2018c). Interpreting and Technology. Berlin: Language Science Press. Furr, M. (2018). Psychometrics: An Introduction. London: Sage.

Goldsmith, J. (2018). Tablet interpreting: Consecutive interpreting 2.0. Translation and Interpreting Studies, v. 13, n. 3, pp. 342-365. 〈https://doi.org/10.1075/tis.00020.gol〉

Hunt-Gómez, C. I.; Gómez Moreno, P. (2015). Reality-based court interpreting didactic material using new technologies. The Interpreter and Translator Trainer, v. 9, n. 2, pp. 188-204. 〈https://doi.org/10.1080/1750399X.2015.1051770〉

ISO 20109. (2016). Simultaneous interpreting - Equipment - Requirements. Geneva: ISO.

ISO/FDIS 20539. (n.d.). Translation, interpreting and related technology - vocabulary. Geneva: ISO.

Kalina, S.; Ziegler, K. (2015). Technology, in: F. Pöchhacker (ed). Routledge Encyclopedia of Interpreting Studies. New York: Routledge, pp. 410-412.

Kerremans, K.; Stengers, H. (2017). Using online and/or mobile virtual communication tools in interpreter and translator training: Pedagogical advantages and drawbacks, in: J. Esteves-Ferreira, et al. (eds). Proceedings of the 39th Conference Translating and the Computer. Geneva: Tradulex, pp. 55-58. 
Kerremans, K., et al. (2019). Technology use by public service interpreters and translators: The link between frequency of use and forms of prior training. FITISPOS International Journal, v. 6, n. 1, pp. 107-122.

Ko, L.; Chen, N. S. (2011). Online interpreting in synchronous cyber classrooms. Babel, v. 57, n. 2, pp. 123-143. 〈https://doi.org/10.1075/babel.57.2.01ko〉

Korpal, P. (2016). Interpreting as a stressful activity: Physiological measures of stress in simultaneous interpreting. Poznan Studies in Contemporary Linguistics, v. 52, n. 2, pp. 297-316. 〈https://doi.org/10.1515/psicl-2016-0011〉

Lee, T. (2014). Using computer-assisted interpreter training methods in Korean undergraduate English classrooms. The Interpreter and Translator Trainer, v. 8, n. 1, pp. 102-122. 〈https://doi.org/10.1080/1750399X.2014.908560〉

Lim, L. (2013). Examining students' perceptions of computer-assisted interpreter training. The Interpreter and Translator Trainer, v. 7, n. 1, pp. 71-89. 〈https://doi.org/10.1080/13556509.2013.798844〉

Mellinger, C. D. (2019). Core research questions and methods, in: E. Angelone; M. Ehrensberger-Dow; G. Massey (eds). Bloomsbury Companion to Language Industry Studies. London: Bloomsbury, pp. 15-35. 〈https://doi.org/10.5040/9781350024960.0006〉

Mellinger, C. D.; Hanson, T. A. (2018). Interpreter traits and the relationship with technology and visibility. Translation and Interpreting Studies v. 13, n. 3, pp. 366392. 〈https://doi.org/10.1075/tis.00021.mel〉

Moser-Mercer, B. (1997). Beyond curiosity: Can interpreting research meet the challenge?, in: J. H. Danks, et al. (eds). Cognitive Processes in Translation and Interpreting. Thousand Oaks, CA: Sage Publications, pp. 176-195.

Moser-Mercer, B. (2008). Skill acquisition in interpreting: A human performance perspective. The Interpreter and Translator Trainer, v. 2, n. 1, pp. 1-28. 〈https://doi.org/10.1080/1750399X.2008.10798764〉

Muñoz Martín, R. (2016). Reembedding translation process research: An introduction, in: R. Muñoz Martín (ed). Reembedding Translation Process Research. Amsterdam: John Benjamins, pp. 1-20. 〈https://doi.org/10.1075/btl.128〉

Muñoz, E.; Calvo, N.; García, A. M. (2019). Grounding translation and interpreting in the brain: What has been, can be, and must be done. Perspectives: Studies in Translation Theory and Practice, v. 27, n. 4, pp. 483-509. 〈https://doi.org/10.1080/0907676X.2018.1549575〉

Napier, J.; Leneham, M. (2011). It was difficult to manage the communication': Testing the feasibility of video remote signed language interpreting in court. Journal of Interpretation, v. 21, n. 1 , article 5. 〈https://doi.org/10.1093/oxfordhb/9780199239306.013.0025〉 
Ortiz, L. E. S.; Cavallo, P. (2018). Computer-assisted interpreting tools (CAl) and options for automation with automatic speech recognition. TradTerm, n. 32, pp. 9-31. 〈https://doi.org/10.11606/issn.2317-9511.v32i0p9-31〉

Plevoets, K.; Defrancq, B. (2016). The effect of informational load on disfluencies in interpreting: A corpus-based regression analysis. Translation and Interpreting Studies, v. 11, n. 2, pp. 202-224. 〈https://doi.org/10.1075/tis.11.2.04ple〉

Plevoets, K.; Defrancq, B. (2018). The cognitive load of interpreters in the European Parliament: A corpus-based study of predictors for the disfluency uh(m). Interpreting, v. 20, n. 1, pp. 1-29. 〈https://doi.org/10.1075/intp.00001.ple〉

Pokorn, N. K.; Mellinger, C. D. (eds). (2018). Community Interpreting, Translation, and Technology: a special issue of Translation and Interpreting Studies, v. 13, n. 3. 〈https://doi.org/10.1075/tis.13.3〉

Roziner, I.; Shlesinger, M. (2010). Much ado about something remote: Stress and performance in remote interpreting. Interpreting, v. 12, n. 2, pp. 214-47. 〈https://doi.org/10.1075/intp.12.2.05roz〉

Sandrelli, A. (2015). Becoming an interpreter: The role of computer technology. MonTI Special Issue 2, pp. 111-138. 〈https://doi.org/10.6035/MonTI.2015.ne2.4〉

Sandrelli, A.; Manuel Jerez, J. de. (2007). The impact of information and communication technology on interpreter training: State-of-the-art and future prospects. The Interpreter and Translator Trainer, v. 1, n. 2, pp. 269-303. 〈https://doi.org/10.1080/1750399X.2007.10798761〉

Setton, R. (2011). Corpus-based Interpreting Studies (CIS): Overview and Prospects, in: A. Kruger; K. Wallmach; J. Munday (eds). Corpus-based Translation Studies: Research and Applications. London: Bloomsbury, pp. 33-75.

Shreve, G. M.; Angelone, E. (2010). Translation and cognition: Recent developments, in: G. M. Shreve; E. Angelone (eds). Translation and Cognition. Philadelphia: John Benjamins, pp. 1-13. 〈https://doi.org/10.1075/ata.xv.01shr〉

Thiemann, D.; Hesse, F. W.; Kozlov, M. (2019). The benefits of collaboration in computer-mediated preference exchange in teams: A psychological perspective. Computers in Human Behavior, v. 97, pp. 24-34. 〈https://doi.org/10.1016/j.chb.2019.02.032〉

Tiselius, E. (2018). Exploring cognitive aspects of competence in sign language interpreting of dialogues: First impressions. Hermes: Journal of Language and Communication in Business, n. 57, pp. 49-61. 〈https://doi.org/10.7146/hjlcb.v0i57.106193〉

Viljanmaa, A. (2018). "Students' views on the use of film-based LangPerform computer simulations for dialogue interpreting. Translation and Interpreting Studies, v. 13, n. 3, pp. 465-485. 〈https://doi.org/10.1075/tis.00025.vil〉 
Warnicke, C.; Plejert, C. (2018). The headset as an interactional resource in a video relay interpreting (VRI) setting. Interpreting, v. 20, n. 2, pp. 285-308. 〈https://doi.org/10.1075/intp.00013.war〉

Wehrmeyer, E. (2019). A corpus for signed language interpreting research. Interpreting, v. 21, n. 1, pp. 62-90. 〈https://doi.org/10.1075/intp.00020.weh〉

Wilmer, H. H.; Sherman, L. E.; Chein, J. M. (2017). Smartphones and cognition: A review of research exploring the links between mobile technology habits and cognitive functioning. Frontiers in Psychology, n. 8, article 605.

〈https://doi.org/10.3389/fpsyg.2017.00605〉

Winteringham, S. T. (2010). The usefulness of ICTs in interpreting practice. The Interpreters' Newsletter, n. 15, pp. 87-99.

Ziegler, Klaus; Gigliobianco, S. (2018). Present? Remote? Remotely present! New technological approaches to remote simultaneous conference interpreting, in: C. Fantinuoli (ed). Interpreting and Technology. Berlin: Language Science Press, pp. 119-139. 